\title{
Minimização do Custo da Produção dos Alimentos de um Restaurante Universitário de Acordo com o Cardápio Diário
}

\author{
Pedro A. M. dos Santos* Nayara B. Zebediff*
}

Glaucia Maria Bressan

\author{
Universidade Tecnológica Federal do Paraná, UTFPR \\ Coordenação do curso de Matemática - Câmpus Cornélio Procópio, PR. \\ E-mails: pedro.mbmazini@gmail.com; nayarazebediff@gmail.com; glauciabressan@utfpr.edu.br
}

\begin{abstract}
RESUMO
O restaurante universitário (RU) da Universidade Tecnológica Federal do Paraná, câmpus Cornélio Procópio, é frequentado por alunos, professores e servidores que realizam suas refeições diariamente. Devido ao aumento do número de usuários, o crescimento do espaço físico e estrutural do restaurante se fez necessário para melhor servi-los. Diante desta realidade, o restaurante deve então produzir uma quantidade maior de refeições para atender a demanda diária de almoço e jantar. O cardápio básico é composto de arroz, feijão, legumes e uma carne. Com o crescimento da produção dos alimentos, surgiu também a preocupação com o aumento de possíveis sobras e com o custo total da produção dos alimentos, o que pode prejudicar o lucro da empresa responsável pelo funcionamento do restaurante. A partir deste contexto, este trabalho propõe a formulação matemática do problema apresentado como um Problema de Programação Linear PPL ([3], [4] e [6]), baseado na formulação do bem conhecido Problema da Dieta, explorado na literatura por [1], [5], [6] e [7]. Desta forma, o problema consiste em minimizar o custo total da produção diária de alimentos do restaurante universitário de maneira que toda a demanda seja atendida. A solução esperada é a quantidade em quilogramas $(\mathrm{kg}) \mathrm{de}$ arroz, feijão, carne e legumes que devem ser produzidos diariamente.

O Problema da Dieta vem sendo explorado na literatura desde 1945 e foi proposto por George Stigler, pioneiro no ramo ([8]). Nesta época, não havia um método que facilitasse os cálculos; porém, Stigler resolveu um amplo conjunto de inequações e obteve a resposta desejada. Mais recentemente, o trabalho de [7] apresenta uma ferramenta para avaliação de modelos matemáticos para a otimização do planejamento de dietas. Resultados da implementação de alguns modelos são obtidos e comparados.

A solução para o problema do restaurante universitário, proposto neste trabalho, é obtida aplicando-se o Método Simplex, ferramenta criada por George Dantzig ([5]), que se trata de um método iterativo de auxílio à tomada de decisões e que pode ser consultado em [2], [4] e [6]. Dantzig necessitava encontrar um bom problema para testar o novo método criado, sendo o problema da dieta de Stigler escolhido para isso. Segundo [6], em linhas gerais, o Método Simplex parte de uma solução básica viável, pertencente a um vértice, do sistema de equações que constituem as restrições do problema. A partir dessa solução inicial, o algoritmo identifica novas soluções viáveis de valor igual ou melhor que a corrente. Assim, o processo encontra novos vértices da envoltória convexa do problema e determina se este vértice é ótimo ou não, ou seja, se a troca de variáveis na base pode ainda melhorar a função objetivo. O problema do restaurante universitário, formulado como um PPL, tem por objetivo minimizar o custo da produção diária de alimentos que atenda à demanda de 1200 refeições diárias, considerando almoço e jantar, e que forneça os nutrientes necessários aos usuários. Os dados do problema, que se referem à quantidade de nutrientes por quilograma de alimento cozido, estão descritos na Tabela 1, assim como o preço por quilograma de alimento. Os dados referentes aos nutrientes são provenientes de [9]. O problema é formulado conforme as equações apresentadas em (1). Nesta formulação, as variáveis de decisão $x_{1}, x_{2}, x_{3}$ e $x_{4}$ representam, respectivamente, as quantidades em quilograma a serem produzidas de arroz, feijão, carne e legumes.
\end{abstract}

*alunos de iniciação científica UTFPR 
Tabela 1: Dados para o modelo do restaurante universitário

\begin{tabular}{|c|c|c|c|c|c|}
\hline Alimento (kg) & Energia (kcal) & Proteína (g) & Carboidrato $(\mathbf{g})$ & Ferro $(\mathbf{m g})$ & Preço por kg \\
\hline Arroz $\left(x_{1}\right)$ & 1300 & 26 & 282 & 1 & 2,30 \\
\hline Feijão $\left(x_{2}\right)$ & 760 & 48 & 136 & 130 & 3,40 \\
\hline Carne $\left(x_{3}\right)$ & 2100 & 320 & 0 & 26 & 9,50 \\
\hline Legumes $\left(x_{4}\right)$ & 273 & 20 & 51 & 4 & 4,60 \\
\hline
\end{tabular}

$\min 2,3 x_{1}+3,4 x_{2}+9,5 x_{3}+4,6 x_{4}$ (função objetivo)

sujeito a (restrições)

$1300 x_{1}+760 x_{2}+2100 x_{3}+273 x_{4} \geq 1920000$

$26 x_{1}+48 x_{2}+320 x_{3}+20 x_{4} \geq 78000$

$282 x_{1}+136 x_{2}+51 x_{4} \geq 411600$

$x_{1}+130 x_{2}+26 x_{3}+4 x_{4} \geq 21600$

Com auxílio do software LINDO $6.1^{1}$, a solução ótima é alcançada com 3 iterações do método simplex, sendo que o custo mínimo é R $\$ 4.711,12$, produzindo-se por dia $1395,26 \mathrm{~kg}$ de $x_{1}$, $133,34 \mathrm{~kg}$ de $x_{2}, 110,38 \mathrm{~kg}$ de $x_{3}$ e $0 \mathrm{~kg}$ de $x_{4}$. A análise do custo reduzido indica que, para que a variável $x_{4}$ deixe de ser nula e se torne básica, seu coeficiente na função objetivo deve ser $0<x_{4} \leq$ 0,89. Comparando o custo ótimo obtido com o custo real, a solução ótima fornece uma economia diária de $\mathrm{R} \$ 687,88$ na produção de alimentos. A análise de sensibilidade fornece intervalos de variação das constantes e dos coeficientes da função objetivo para os quais a base permanece inalterada. A variação das constantes das restrições pode ocorrer nos intervalos: $0<$ $1920000 \leq 2146992,4 \mathrm{kcal} ; 43744,5 \leq 78000 \leq 285831,1 \mathrm{~g} ; 354877 \leq 411600 \leq 790177,6 \mathrm{~g}$ e $4713,73 \leq$ $21600 \leq 147742,07 \mathrm{mg}$. Também na função objetivo, o custo do $\mathrm{kg}$ das variáveis $x_{1}, x_{2}, x_{3}$ e $x_{4}$ pode variar nos intervalos $0,75 \leq x_{1} \leq 4,86 ; 2,16 \leq x_{2} \leq 48,3 ; 0,46 \leq x_{3} \leq 20,67$ e $0,89 \leq x_{4}$. Por exemplo, atribuindo-se $x_{1}=4,86$ na função objetivo, o custo ótimo passa a ser $\mathrm{R} \$ 8283$. Como perspectivas de continuidade deste trabalho, dados reais estão sendo coletados no restaurante universitário para que outras restrições práticas sejam incorporadas ao problema, como um horizonte de planejamento multiperíodo. Além disso, pretende-se verificar a viabilidade de se propor cardápios vegetarianos para analisar o impacto no custo de tal diversificação.

Palavras-chave: Otimização Linear, Problema da Dieta, Restaurante Universitário.

\section{Referências}

[1] V.M.B. Araújo; L.F.R. Souza, Modelagem Matemática aplicada a dietas alimentares e estudo de obesidade. Revista Eletrônica de Educação e Ciência, 02:01, (2012), 30-43.

[2] M.N. Arenales; V. Armentano; R. Morabito; H. Yanasse, H. "Pesquisa Operacional para Cursos de Engenharia". Rio de Janeiro, Elsevier, 2007.

[3] M.S.Bazaraa; J.J Jarvis; H.D Sherali, “Linear Programming and Network Flows”,Wiley, 2004

[4] G.B. Dantzig, "Linear Programming and Extensions", Princeton University Press, Princeton, New Jersey, 1963.

[5] G.B. Dantzig, The Diet Problem. Interfaces, 20:4, (1990) 43-47.

[6] M.C. Goldbarg; H.P.L. Luna, "Otimização Combinatória e Programação Linear - modelos e algoritmos", Rio de Janeiro: Campus, 2005.

[7] A.A. Namen; C.T. Bornsteim, Uma ferramenta para avaliação de resultados de diversos modelos de otimização de dietas. Pesquisa Operacional, 24:3, (2004), 445-465.

[8] G. Stigler, The Cost of Subsistence. Journal of Farm Economics, 25, (1945)303-314.

[9] Tabela brasileira de composição de alimentos / Núcleo de Estudos e Pesquisas em Alimentação.Versão II. - 2. ed. - Campinas, SP: NEPA-UNICAMP, 2006. 113 pg.

\footnotetext{
1 "Linear Interactive and Discrete Optimizer". Disponível em <www.lindo.com>
} 